\title{
HUBUNGAN ANTARA KASUS MALARIA DENGAN KONDISI SANITASI RUMAH TEMPAT TINGGAL DI PUSKESMAS PASAR MANNA KABUPATEN BENGKULU SELATAN
}

\author{
Elvi Hayani $^{1)}$, Agus M.H.Putranto ${ }^{2)}$, Puji Harsono ${ }^{3)}$ \\ ${ }^{1)}$ Puskesmas M. Thaha Kabupaten Bengkulu Selatan \\ ${ }^{2)}$ Dosen Jurusan MIPA Fakultas MIPA UNIB \\ ${ }^{3)}$ Dosen Jurusan Budidaya Pertanian Fakultas Pertanian UNIB
}

\begin{abstract}
ABSTRAK
Telah dilakukan penelitian dengan judul Hubungan antara Kasus Malaria dengan Kondisi Sanitasi Rumah Tempat Tinggal di Puskesmas Pasar Manna Kabupaten Bengkulu Selatan. Adapun tujuan penelitian ini untuk mengetahui hubungan antara kasus malaria dengan kondisi sanitasi rumah tempat tinggal. Dengan menggunakan metode kasus kontrol (case control) yaitu penelitian survei analitik dimana subjek yaitu kasus dan kontrol telah diketahui dan dipilih berdasarkan sifat tertentu dan telah mempunyai keluaran (outcome) tertentu, lalu dilihat kebelakang (backward) tentang riwayat status paparan penelitian yang dialami subjek. Sampel pada penelitian ini merupakan total sampling yaitu penderita malaria sebanyak 25 orang sebagai kasus dan warga yang dinyatakan negatif malaria sebanyak 25 orang sebagai kontrol di Wilayah Puskesmas Pasar Manna Kecamatan Pasar Manna Bengkulu Selatan. Dan hasilnya terdapat hubungan yang signifikan antara kebersihan rumah terhadap kejadian malaria dengan hasil analisis menunjukkan $\mathrm{R}=0,801$ dan nilai $\mathrm{p}=0,000$.Terdapat hubungan yang signifikan antara ventilasi terhadap kejadian malaria dengan hasil analisis menunjukkan $\mathrm{R}=0,881$ dan nilai $\mathrm{p}=0,000$. Terdapat hubungan yang signifikan antara genangan air terhadap kejadian malaria dengan hasil analisis menunjukkan $\mathrm{R}=0,840$ dan nilai $\mathrm{p}=$ 0,000.Terdapat hubungan yang signifikan antara keadaan gantungan baju terhadap kejadian malaria dengan hasil analisis menunjukkan $\mathrm{R}=0,801$ dan nilai $\mathrm{p}=0,000$. Ventilasi kawat kasa merupakan sanitasi rumah yang sangat berpengaruh pada kejadian malaria di Kecamatan Pasar Manna.
\end{abstract}

Kata Kunci: Kasus Malaria, Sanitasi Rumah

\section{PENDAHULUAN}

Pembangunan kesehatan diarahkan untuk meningkatkan kualitas sumber daya manusia, kualitas kehidupan manusia, meningkatkan kesejahteraan manusia dan masyarakat serta untuk mempertinggi kesadaran masyarakat akan pentingnya hidup sehat. Sarana dan kebijakan pembangunan perumahan dewasa ini dirasakan pada golongan masyarakat yang berpenghasilan rendah, daerah kumuh, perkotaan, daerah pedesaan dan daerah terpencil (Haris, 2007).
Manusia membutuhkan rumah sebagai tempat untuk berteduh atau berlindung dari gangguan cuaca atau kondisi iklim yang kurang sesuai dengan tubuh manusia, untuk beristirahat mengadakan kegiatan rutin untuk memenuhi kesehatan jasmani bagi kelangsungan hidup seperti mandi, makan, tidur, juga tempat untuk berkumpul dengan seluruh keluarga dan lain-lain. Rumah mempunyai berbagai fungsi yang sangat penting bagi kehidupan manusia, maka rumah dan kondisi lingkungannya yang tidak sehat dapat mempengaruhi derajat kesehatan jasmani maupun rohani 
bagi para penghuninya juga akan mempermudah timbulnya berbagai macam penyakit (Azrul, 1990).

Perumahan yang sehat adalah perumahan yang memenuhi persyaratan antara lain memenuhi kebutuhan psikologis, memenuhi kebutuhan fisiologis, mencegah penularan dan mencegah kejadian kecelakaan. Dari hasil data statistik pembangunan perumahan di Indonesia tahun 1984, lembaga pembangunan rumah baik swasta maupun pemerintah hanya menyediakan $15 \%$ dari kebutuhan rumah, selebihnya dibangun oleh masyarakat sendiri, selanjutnya pada tahun 1990 lembaga pembangunan rumah swasta dan pemerintah membangun 706.939 unit rumah. Angka tersebut sangat kecil bila dibandingkan dengan kebutuhan penduduk akan perumahan sehat (Depkes RI, 1999).

Salah satu penyakit yang ditimbulkan akibat rumah yang tidak sehat adalah Malaria. Penyakit malaria merupakan penyakit yang erat kaitannya dengan kondisi sanitasi rumah seperti tidak memasang kawat kasa pada ventilasi, kondisi sarana air bersih, kondisi tempat pembuangan sampah dan kondisi sarana pembuangan air limbah, keadaan gantungan baju, genangan air di sekitar rumah, jarak rumah dengan waduk/embung, jarak rumah dengan air payau/rawa-rawa hal ini akan berisiko menyebabkan penyakit malaria (Kusnindar, 1990).

Sejak tahun 1968, upaya pencegahan penyakit malaria telah diintegrasikan kedalam sistem kesehatan yang ada. Dimana pelaksanaan operasional diselenggarakan oleh Puskesemas dan jajaran lainnya di kecamatan dan di tingkat desa dengan bantuan dan bimbingan dari kabupaten dan provinsi (Depkes RI, 2003).

Upaya untuk menekan angka kesakitan dan kematian malaria dilaksanakan melalui program pencegahan malaria yang kegiatannya meliputi perbaikan kondisi sanitasi rumah masyarakat, penggunaan kelambu, pemasangan kawat kasa pada ventilasi rumah, menjaga kondisi sarana penampungan air, memperhatikan kebersihan tempat pembuangan sampah dan kebersihan saluran Pembuangan Air Limbah (SPAL) yang kesemuanya ditujukan untuk memutus mata rantai penularan malaria (Depkes RI, 2003 ).

Penyakit malaria erat kaitanya dengan sanitasi perumahan yang tidak sehat dan tidak memenuhi syarat kesehatan, sehingga mendatangkan risiko seseorang mengalami penyakit-penyakit yang berbasis lingkungan seperti malaria (Depkes. 2003). Penyebaran penyakit malaria di Kabupaten Bengkulu Selatan, mencakup semua wilayah pegunungan dan daratan rendah, penyakit malaria paling banyak ditemukan di daerah pantai dan daerah pedalaman.

Penyebabnya adalah adanya tempat perkembangan nyamuk Anopheles sebagai vektor penyakit malaria yang berada di sekitar pemukiman penduduk. Tempattempat perkembangbiakan nyamuk Anopheles yang paling disenangi antara lain kolam, muara sungai, dan rawa-rawa. Kasus malaria di Puskesmas Pasar Manna pada tahun 2011 ada 178 orang, jumlah penderita yang klinis malaria mencapai 135 orang, sedangkan penderita malaria positif ada 25 orang (Laporan Tahunan Puskesmas Pasar Manna Tahun 2011).

Tujuan mum penelitian ini adalah untuk mengetahui hubungan antara kasus malaria dengan kondisi sanitasi rumah tempat tinggal di wilayah kerja Puskesmas Pasar Manna Kecamatan Pasar Manna Kabupaten Bengkulu Selatan Tahun 2011. Tujuan Khususpenelitian ini adalah untuk menganalisis hubungan antara kasus malaria dengan kebersihan rumah tempat tinggal di wilayah kerja Puskesmas Pasar Manna Kecamatan Pasar Manna Kabupaten Bengkulu Selatan Tahun 2011, menganalisis hubungan antara kasus malaria dengan ventilasi kawat kasa rumah tempat tinggal di wilayah kerja Puskesmas Pasar Manna Kecamatan Pasar Manna Kabupaten Bengkulu Selatan Tahun 2011, menganalisis hubungan antara kasus malaria dengan genangan air di rumah 
tempat tinggal di wilayah kerja Puskesmas Pasar Manna Kecamatan Pasar Manna Kabupaten Bengkulu Selatan Tahun 2011, menganalisis hubungan antara kasus malaria dengan keadaan gantungan baju di rumah tempat tinggal di wilayah kerja Puskesmas Pasar Manna Kecamatan Pasar Manna Kabupaten Bengkulu Selatan Tahun 2011.

\section{METODE}

Penelitian dilaksanakan pada bulan Februari sampai dengan Maret 2012 di Wilayah Puskesmas Pasar Manna Kecamatan Pasar Manna Bengkulu Selatan. Sampel pada penelitian ini merupakan total sampling yaitu 50 orang masyarakat yang di duga penderita malaria sebanyak 25 orang sebagai kasus yaitu masyarakat yang positif malaria dan warga yang dinyatakan negatif malaria sebanyak 25 orang sebagai kontrol di Wilayah Puskesmas Pasar Manna Kecamatan Pasar Manna Bengkulu Selatan.

Data primer dikumpulkan dengan cara wawancara kepada responden. Responden melalui data pendukung dari laporan atau register penderita malaria yang berobat ke puskesmas melalui laporan triwulan dan tahunan Puskesmas Pasar Manna Kabupaten Bengkulu Selatan. Kemudian peneliti datang kerumah responden, data yang dikumpulkan adalah kebersihan rumah, ventilasi kawat kasa, genangan air dan keadaan gantungan baju. Data sekunder berupa dokumentasi dari Dinas Kesehatan Kabupaten Bengkulu Selatan. Observasi dan pengukuran dilaksanakan untuk mengetahui variabel kondisi kesehatan lingkungan rumah responden. Untuk mengetahui peran hubungan antara variabel bebas dan variabel terikat dengan menggunakan uji regresi logistik dengan melihat hasil analisis bivariat yang mempunyai kemaknaan statistik $(\mathrm{P}<0,25)$ dan kemaknaan biologi. Untuk uji kemaknaan kaitan antara variabel yang diteliti terhadap variabel terpengaruh dilihat dari P-Value $<0,01$ pada $=99 \%$ dengan persamaan sebagai berikut :

$$
\mathrm{Y}=\mathrm{a}+\mathrm{b}_{1} \mathrm{X}_{1}+\mathrm{b}_{2} \mathrm{X}_{2}+\mathrm{b}_{3} \mathrm{X}_{3}+\mathrm{b}_{4} \mathrm{X}_{4}
$$

\section{HASIL DAN PEMBAHASAN}

Penelitian dilakukan pada kelompok kasus dan kontrol. Adapun kebersihan rumah yang terdapat pada rumah responden baik kelompok kasus maupun kelompok control terdapat pada kelompok kasus yang tidak memenuhi syarat kebersihan rumah $88 \%$ dan yang memenuhi syarat kebersihan rumah $12 \%$. Sedangkan pada kontrol terdapat $8 \%$ rumah yang tidak bersih dan 92\% memenuhi syarat kebersihan rumah. Adapun ventilasi kawat kasa yang terdapat pada rumah responden baik kelompok kasus maupun kelompok control dapat dilihat bahwa pada kelompok kasus yang tidak memakai kasa $92 \%$ dan yang memakai kasa $8 \%$. Sedangkan pada kontrol terdapat $4 \%$ yang tidak memakai kasa dan 96\% memakai kasa. Adapun genangan air yang terdapat pada rumah responden baik kelompok kasus maupun kelompok control dapat dilihat bahwa pada kelompok kasus yang ada genangan air 92\% dan yang tidak ada genangan air $8 \%$. Sedangkan pada kontrol terdapat $8 \%$ ada genangan air dan $92 \%$ tidak ada genangan air. Adapun keadaan gantungan baju yang terdapat pada rumah responden baik kelompok kasus maupun kelompok control dapat dilihat bahwa pada kelompok kasus yang ada gantungan $88 \%$ dan yang tidak ada gantungan $12 \%$. Sedangkan pada kontrol terdapat $8 \%$ ada gantungan dan 92 tidak ada gantungan sebagai tempat hinggap nyamuk. Faktor sanitasi rumah yaitu kebersihan, ventilasi, genangan air dan gantungan baju dihubungkan dengan kejadian malaria menggunakan analisis linier berganda. Hal ini menggambarkan adanya hubungan antara faktor sanitasi rumah yaitu kebersihan, ventilasi, genangan air dan gantungan baju terhadap 
kejadian malaria. perhitungan regresi linier berganda dapat dihitung dengan menggunakan persamaan sebagai berikut (Tabel 1):

$$
\begin{gathered}
\mathrm{Y}=-0,072+0,237 \mathrm{X}_{1}+0,358 \mathrm{X}_{2}+0,278 \mathrm{X}_{3} \\
+0,237 \mathrm{X}_{4}
\end{gathered}
$$

Pada penelitian ini ventilasi kawat kasa merupakan faktor yang paling berpengaruh terhadap kejadian malaria dikarenakan memiliki nilai koeefisien regresi terbesar terhadap indikasi penyakit malaria dan dibuktikan pula dengan jumlah responden yang tidak memiliki kawat kasa mendominasi terjangkitnya malaria.

Dari hasil analisis regresi didapatkan bahwa variabel kebersihan rumah mempengaruhi kejadian malaria. Hal ini dilihat dari nilai $\mathrm{t}$ hitung $>\mathrm{t}$ tabel yaitu $4,100>2,867$ yang menunjukkan bahwa kebersihan rumah berpengaruh nyata terhadap kejadian malaria pada taraf signifikan $1 \%$. Hasil analisis regresi menunjukan adanya hubungan signifikan antara $\mathrm{Y}$ dan $\mathrm{X}$, sehingga adanya hubungan antara $\mathrm{Y}$ dengan $\mathrm{X}_{1}, \mathrm{X}_{2}, \mathrm{X}_{3}, \mathrm{X}_{4}$. Sistem bangunan yang dimiliki memungkinkan agar rumah bebas kotoran, debu, asap serta kontaminan lainnya. Rumah yang berada di dekat jalan raya jelas berbeda penanganannya dengan rumah yang ada di kompleks persawahan. Berbagai aktivitas pembangunan dapat memungkinkan timbulnya tempat perindukan nyamuk yang menjadi buatan manusia sendiri.

Dari hasil analisis regresi didapatkan bahwa variabel ventilasi kawat kasa mempengaruhi kejadian malaria. Hal ini dilihat dari nilai $\mathrm{t}$ hitung $>\mathrm{t}$ tabel yaitu $5,386>2,867$ yang menunjukkan bahwa ventilasi kawat kasa berpengaruh nyata terhadap kejadian malaria pada taraf signifikan $1 \%$. Hasil penelitian menunjukkan bahwa rumah yang tidak memakai kawat kasa lebih banyak pada kelompok kasus dibanding pada kelompok kontrol. Dari hasil analisis regresi didapatkan bahwa variabel genangan air mempengaruhi kejadian malaria. Hal ini dilihat dari nilai $\mathrm{t}$ hitung $>\mathrm{t}$ tabel yaitu 4,497 > 2,867 yang menunjukkan bahwa genangan air berpengaruh nyata terhadap kejadian malaria pada taraf signifikan $1 \%$. Hasil penelitian menunjukkan bahwa rumah yang ada genangan air lebih banyak pada kelompok kasus dibanding pada kelompok kontrol. Analisis statistika menunjukkan $\mathrm{p}=0,000$ yang bermakna $\mathrm{p}<$ 0,01 dengan demikian dapat dinyatakan bahwa genangan air mempunyai pengaruh terhadap kejadian malaria. Koefisien regresi variabel genangan air bernilai positif (b) yaitu 0,278 artinya setiap peningkatan 1 satuan tanpa genangan air maka menurunkan kejadian malaria sebesar 27,8\%. Tempat perindukan nyamuk adalah genangan air, bak air tawar maupun air payau, tergantung dari jenis nyamuknya, air tidak boleh tercemar atau terpolusi dan harus selalu berhubungan dengan tanah. Tempat perindukan ini dipengaruhi oleh beberapa faktor seperti kadar garam, kejernihan dan flora. Tempat perindukan vektor di air payau terdapat di muara-muara sungai yang tertutup hubungannya ke laut dan rawa-rawa merupakan daerah yang cocok untuk tempat perindukan Anopheles sundaicus dan Anopheles subpictus, sedangkan tempat perindukan air tawar berupa sawah, mata air, terusan, genangan di tepi sungai,

Tabel 1. Hubungan antar faktor sanitasi rumah terhadap kejadian malaria

\begin{tabular}{ccccc}
\hline Variabel & B & Beta & t & Sig (P) \\
\hline Konstanta & $-0,072$ & & 2,323 & 0,025 \\
Kebersihan rumah $\left(\mathrm{X}_{1}\right)$ & 0,237 & 0,237 & 4,100 & 0,000 \\
Ventilasi kasa $\left(\mathrm{X}_{2}\right)$ & 0,358 & 0,358 & 5,386 & 0,000 \\
Genangan air $\left(\mathrm{X}_{3}\right)$ & 0,278 & 0,278 & 4,497 & 0,000 \\
Gantungan baju $\left(\mathrm{X}_{4}\right)$ & 0,237 & 0,237 & 4,100 & 0,000 \\
\hline $\mathrm{R}^{2}=0,929$ & & & $\mathrm{~F}=146,481$ \\
\hline
\end{tabular}

(Sumber: Data Primer setelah di olah, 2012) 
bekas jejak kaki, roda kendaraan, dan bekas lubang galian cocok untuk tempat berkembang biak Anopheles aconites, Anopheles maculates, dan Anopheles balbacencis (Myrnawati, 2000).

Berdasarkan analisis regresi dapat dilihat bahwa nilai korelasi yang paling signifikan adalah faktor ventilasi kawat kasa dengan nilai 0,881 . Analisa statistika menunjukkan $\mathrm{p}=0,000$ yang bermakna $\mathrm{p}<$ 0,01 dengan demikian dapat dinyatakan bahwa ventilasi kawat kasa mempunyai pengaruh terhadap kejadian malaria. Koefisien regresi variabel ventilasi kawat kasa bernilai positif (b) yaitu 0,358 artinya setiap peningkatan 1 satuan pemakaian kawat kasa maka menurunkan kejadian malaria sebesar 35,8\%. Hal ini menunjukkan bahwa ventilasi kawat kasa merupakan kondisi sanitasi rumah yang sangat berpengaruh terhadap kejadian malaria di wilayah kerja Puskesmas Pasar Manna. Dibuktikan dengan responden yang tidak memiliki kawat kasa mendominasi terjangkitnya malaria. Ventilasi merupakan jalan masuk keluarnya udara, hal ini juga dimanfaatkan nyamuk untuk dapat masuk ke dalam ruangan. Agar udara tetap masuk dan nyamuk tidak dapat masuk secara bebas maka ventilasi ditutupi dengan kawat kasa (Myrnawati, 2000).

Dari hasil analisis regresi didapatkan bahwa variabel gantungan baju mempengaruhi kejadian malaria. Hal ini dilihat dari nilai $\mathrm{t}$ hitung $>\mathrm{t}$ tabel yaitu 4,497 > 2,867 yang menunjukkan bahwa gantungan baju berpengaruh nyata terhadap kejadian malaria pada taraf signifikan $1 \%$. Hasil penelitian menunjukkan bahwa rumah yang ada gantungan baju lebih banyak pada kelompok kasus dibanding pada kelompok kontrol. Analisis statistika menunjukkan $\mathrm{p}$ $=0,000$ yang bermakna $\mathrm{p}<0,01$ dengan demikian dapat dinyatakan bahwa gantungan baju mempunyai pengaruh terhadap kejadian Malaria.

Koefisien regresi variabel gantungan baju bernilai positif (b) yaitu 0,237 artinya setiap peningkatan 1 satuan tanpa gantungan baju maka menurunkan kejadian malaria sebesar $23,7 \%$. Nyamuk sangat menyukai gantungan baju sebagai tempat hinggap. Disamping tempat yang nyaman, baju yang digantung biasanya sudah berbau sehingga semakin memancing daya tarik nyamuk (Myrnawati, 2000).

Keempat variabel di atas memiliki hubungan keeratan yang nyata dan kuat $(0,5 \leq \mathrm{C} \leq 0,75)$ yaitu 0,625 untuk kebersihan rumah, 0,661 untuk ventilasi kawat kasa, 0,643 untuk genangan air dan 0,625 untuk gantungan baju. Sedangkan berdasarkan hasil analisis risiko kejadian malaria didapatkan nilai odds ratio (OR) kebersihan rumah 84,333, ventilasi kawat kasa 276,000, genangan air 132,250 dan gantungan baju 84,333 . Ini berarti sanitasi rumah (kebersihan rumah, ventilasi kawat kasa, genangan air dan gantungan baju) merupakan faktor risiko kejadian malaria (Tabel 2).

\section{KESIMPULAN}

Dari hasil dan pembahasan penelitian maka penelitian dapat menyimpulkan bahwa ventilasi kawat kasa merupakan kondisi sanitasi rumah yang sangat berpengaruh terhadap kejadian malaria di Kecamatan Pasar Manna dengan hasil analisis menunjukkan $\mathrm{R}=0,881$ dan nilai $\mathrm{p}=0,000$.

Tabel 2. Hubungan antar variabel independen terhadap kejadian malaria

\begin{tabular}{cccc}
\hline Variabel & $\chi^{2}$ & $\mathrm{C}$ & OR \\
\hline Kebersihan rumah $\left(\mathrm{X}_{1}\right)$ & 32,051 & 0,625 & 84,333 \\
Ventilasi kasa $\left(\mathrm{X}_{2}\right)$ & 38,782 & 0,661 & 276,000 \\
Genangan air $\left(\mathrm{X}_{3}\right)$ & 35,280 & 0,643 & 132,250 \\
Gantungan baju $\left(\mathrm{X}_{4}\right)$ & 32,051 & 0,625 & 84,333 \\
\hline
\end{tabular}

(Sumber: Data Primer setelah di olah, 2012) 


\section{DAFTAR PUSTAKA}

Azrul. A. 1990. Pengantar Ilmu Kesehatan Lingkungan, Jakarta: Mutiara Sumber Widya.

Depkes. RI. 1999. Pedoman Pelaksanaan Pengawasan dan Pengendalian Dampak Sampah (Aspek Kesehatan Lingkungan). Jakarta.

Depkes. RI. 2003. Pedoman Tata Laksana Kasus Malaria, Gebrak Malaria. Jakarta.

Dinas Kesehatan Kabupaten Bengkulu Selatan 2011, Laporan Tahunan Puskesmas Pasar Manna Tahun 2011
Haris, Sahri, Lalu. 2007. Penyehatan Perumahan dan Permukiman, Mataram: FKM-UNTB.

Kusnindar. 1990. Masalah Malaria dan Pemberantasannya di Indonesia. Cermin Duinia Kedokteran No.63:712

Kusnoputranto, Haryoto, 1985. Kesehatan Lingkungan. FKM UI, Jakarta.

Myrnawati, 2000. Epidemiologi. Jakarta: Ilmu Kesehatan Masyarakat.

Widoyono. 2008. Penyakit Tropis, Epidemiologi, Penularan, Pencegahan dan Pemberantasanya. Penerbit Erlangga. Jakarta. 